DOI: $10.17516 / 1997-1370-0852$

УДК 343.8

\title{
Problems of Legal Regulation of the Implementation of Fixed Assets of Legal Entities, Serving Sentences as an Incentive for Law-abiding Behavior of Those Sentenced to Imprisonment, Respect for Individual Rights
}

\author{
Valery N. Belika, Nikolay N. Kutakov ${ }^{\mathrm{b}}$ \\ and Dmitry G. Metlin*b \\ ${ }^{a}$ Financial University under the Government of the Russian Federation \\ Moscow, Russian Federation \\ ${ }^{b}$ Academy of Law Management of the Federal Penal Service of Russia \\ Ryazan, Russian Federation
}

Received 15.04.2020, received in revised form 21.08.2020, accepted 14.09.2021

\begin{abstract}
The aim of the work is to study criminal-executive relations in the field of application of the basic means of correction to convicts serving a sentence of imprisonment. The analysis of the legal basis for the implementation of fixed assets for the correction of convicts established by the criminal executive legislation of Russia is carried out. There is a deficiency in the legal regulation of certain remedies, including social impact and educational work with prisoners. This circumstance is a significant obstacle to their implementation in practice, which negatively affects the formation of law-abiding behavior of persons serving a prison sentence, as well as the observance of rights. A number of recommendations are made, aimed at improving the criminal-executive policy in this area, including on the basis of the analysis of the legal support of remedies for convicted countries of the Commonwealth of Independent States convicted under the law.
\end{abstract}

Keywords: deprivation of liberty, convicted person, means of correction, public influence, educational work, law-abiding behavior, observance of rights.

Research area: law.

Citation: Belik, V.N., Kutakov, N.N., Metlin D. G. (2021). Problems of legal regulation of the implementation of fixed assets of legal entities, serving sentences as an incentive for law-abiding behavior of those sentenced to imprisonment, respect for individual rights. J. Sib. Fed. Univ. Humanit. soc. sci., 14(11), 1720-1730. DOI: 10.17516/1997-1370-0852

(C) Siberian Federal University. All rights reserved

* Corresponding author E-mail address: diman-metlin1992@mail.ru 


\title{
Проблемы правового регулирования
}

\section{реализации основных средств исправления лиц, отбывающих наказание, как стимула правопослушного поведения осуждённых к лишению свободы, соблюдения прав личности}

\author{
В.Н. Белика, Н.Н. Кутаков ${ }^{6}$, Д.Г. Метлинб \\ ${ }^{a}$ Финансовый университет при Правительстве Российской Федераџии \\ Российская Федерация, Москва \\ ${ }^{6}$ Академия права и управления Федеральной службы исполнения наказаний \\ Российская Федераиия, Рязань
}

\begin{abstract}
Аннотация. Целью работы является исследование уголовно-исполнительных отношений в сфере применения основных средств исправления к осужденным, отбывающим наказание в виде лишения свободы.Проводится анализ правовых основ реализации основных средств исправления осужденных, установленных уголовноисполнительным законодательством России. Отмечается недостаток в правовом регулировании отдельных средств исправления, в числе которых общественное воздействие и воспитательная работа с осужденными. Данное обстоятельство является значительным препятствием на пути их реализации в практической деятельности, что отрицательно сказывается на формировании правопослушного поведения лиц, отбывающих лишение свободы, а также соблюдении прав. Высказывается ряд рекомендаций, направленных на совершенствование уголовно-исполнительной политики в данной сфере, в том числе на основе проведенного анализа правового обеспечения средств исправления осужденных по законодательству стран - участников Содружества Независимых Государств.
\end{abstract}

Ключевые слова: лишение свободы, осужденный, средства исправления, общественное воздействие, воспитательная работа, правопослушное поведение, соблюдение прав.

Научная специальность: 12.00 .00 - юридические науки.

\section{Введение в проблему исследования}

Уголовно-исполнительное законодательство Российской Федерации одной из своих главных целей имеет исправление осужденных. Исправление осужденных (как цель уголовной ответственности и применения наказания) подразумевает формирование у них уважительного отношения к человеку, обществу, труду, нормам, правилам и традициям человеческого общежития и стимулирование правопослушного поведения. Достижение указанной цели предполагается за счет применения конкретных средств исправления, к которым законодатель относит установленный порядок исполнения и отбывания наказания (режим), воспитательную работу, общественно полезный труд, получение общего образования, профессиональное обучение и общественное воздействие на осужденных (ч. 2, ст. 9 УИК РФ).

Основные средства исправления служат для того, чтобы осужденный в период отбывания наказания приобрел навыки и умения, которые способствовали бы его успешной ресоциализации после освобождения от наказания (Mikhlin, Seliverstov, 2008: 43). Однако практика их реализации на протяжении истории исполнения наказания в виде лишения свободы сталкивается с рядом проблемных вопросов, обусловленных спецификой государственной политики в области исполнения уголовных нака- 
заний в различный исторический период (Utkin, 2019), переустройством отечественной пенитенциарной системы (Uporov, 2017; Teplyashin, 2020), трудной социальнокриминологической характеристикой преступников, содержащихся в местах лишения свободы, и другими факторами. Все это в совокупности сказывается на эффективности деятельности пенитенциарной системы по достижении главной цели - исправлению осужденных за счет воздействия совокупности определенных законодательством средств. Главным критерием достижения цели исправления, как отмечает профессор Селиверстов, «может быть только правопослушное поведение в аспекте соблюдения запрета на совершение преступлений. Показателем такого критерия является уровень постпенитенциарной рецидивной преступности, однако с определенной степенью условности, поскольку совершение рецидивных преступлений во многом определяется социальными условиями жизни после освобождения из исправительного учреждения» (Seliverstov, 2018: 68). Так, согласно статистическим данным ФСИН России, в 2019 г. в исправительных колониях различных видов количество лиц, отбывающих лишение свободы второй и более раз, составило 228,1 тыс. человек. Таким образом, доля рецидивистов в 2019 г. среди осужденных в исправительных колониях равнялась 53,7 \% от общего количества отбывающих лишение свободы (Federal Penitentiary Service, 2020).

Стоит заметить, что в разное время, c учетом уголовно-исполнительной политики государства, вопрос правового регулирования и особенностей применения средств исправления к осужденным в местах лишения свободы оставался актуальным в научной сфере и продолжает вызывать научный интерес. В прежних научных исследованиях находили отражение как общие положения процесса исправления осужденных к лишению свободы (Vishnevskaya, 2006), так и совершенствование применения отдельных средств исправления (Matveenko, 2000; Bebein, 2008). Вместе с тем, отсутствие каких-либо значи- мых правовых решений в рассматриваемой сфере уголовно-исполнительных правоотношений с вступлением в силу УИК РФ (1997 г.), а также проблемы, возникающие в процессе исполнения (отбывания) лишения свободы, определяют потребность настоящего исследования, сосредоточив особое внимание на правовом регулировании и реализации таких средств исправления лиц, отбывающих наказание в виде лишения свободы, как воспитательная работа и общественное воздействие.

\section{Постановка проблемы}

Законодательное выражение основных средств исправления осужденных в теории должно предполагать самостоятельное правовое обеспечение в отдельности каждого из них. Однако в содержании Особенной части УИК РФ в отдельных главах свое отражение нашли лишь некоторые из них, такие как установленный порядок исполнения и отбывания наказания (режим), воспитательная работа, общественно полезный труд и профессиональное обучение осужденных. При этом отдельные нормы, посвященные деятельности общественных институтов по исправлению осужденных, встречаются в разных главах уголовноисполнительного закона. По нашему мнению, подобный подход ставит под сомнение правильность выделения общественного воздействия в качестве самостоятельного средства исправления.

В достижении цели исправления осужденных речь прежде всего стоит вести о нравственном исправлении преступника как наиболее труднодостижимом, но качественном результате. При этом важно подчеркнуть, что эффективность воздействия установленных законом средств исправления возможна лишь при непосредственном и активном участии самих осужденных в процессе их реализации, то есть это двухсторонний процесс. Однако анализ норм отечественного уголовно-исполнительного законодательства, регулирующих применение средств исправления, показал совершенно разные объемы элемента обязательного участия в них осужденных, 
отбывающих лишение свободы. Таким образом, данное обстоятельство крайне негативно сказывается на практике исполнения уголовного наказания в виде лишения свободы. Так, например, осужденные нередко отказываются выполнять законные требования сотрудников администрации исправительных учреждений, а именно принимать участие в различных мероприятиях воспитательного характера, аргументируя свои действия тем, что данные мероприятия не предусмотрены распорядком дня исправительного учреждения. Как правило, подобные случаи перетекают в конфликтные ситуации между сотрудниками администрации и осужденными, исходом которых является принуждение к участию или применение мер дисциплинарного воздействия.

Подобная неточность в правовом регулировании в рациональном использовании элемента обязательного участия осужденных в реализации основных средств исправления, на наш взгляд, выступает серьезной проблемой в достижении ведущей цели уголовно-исполнительного законодательства России.

\section{Обсуждение}

В научных исследованиях в области уголовно-исполнительного права, посвященных порядку исполнения (отбывания) лишения свободы, под правовым регулированием основных средств исправления осужденных понимается такое воздействие, при котором в законодательных актах и нормативных актах ведомств, осуществляющих руководство уголовноисполнительной системой, ставится ясно обозначенная цель - их исправление (Kirillova, 2020: 28). Не является исключением и такое средство, как установленный порядок исполнения и отбывания наказания (режим). Один из элементов режима заключается в обязанности осужденных выполнять требования, установленные в статьях уголовно-исполнительного закона. Данные требования, прежде всего, определяют правовой статус осужденного (ст. 11 УИК РФ), а также посвящены регулированию кон- кретных аспектов исполнения наказания в виде лишения свободы, например в Главе 12 УИК РФ «Режим в исправительных учреждениях и средства его обеспечения». По мнению профессора В.Е. Южанина, «режим отбывания наказания - это твердо установленный распорядок жизни, труда, учебы и отдыха осужденных к лишению свободы, а также порядок реализации карательных условий отбывания наказания» (Yuzanin, 2018: 18).

Конкретизация требований режима раскрывается в подзаконных нормативных правовых актах. Так, соответствующие нормы в большей своей части закреплены в Правилах внутреннего распорядка исправительного учреждения (далее - ПВР ИУ), утвержденных приказом Министерства юстиции РФ от 16 декабря 2016 г. № 295, в которых в пункте 16 «Осужденные обязаны» перечислены основные из них:

- соблюдать распорядок дня, установленный в исправительном учреждении;

- выполнять законные требования работников УИС;

- соблюдать требования пожарной безопасности; и учебе;

- добросовестно относиться к труду

- быть вежливыми между собой и в общении с сотрудниками УИС и иными лицами;

- носить одежду установленного образца с нагрудными отличительными знаками и др.

Предполагается, что основная роль режима как средства исправления заключается в привитии навыков дисциплины и упорядоченного поведения осужденным в период отбывания лишения свободы, соблюдения правил санитарии и гигиены и вежливого отношения к персоналу, иным лицам, посещающим учреждения, а также к другим осужденным. Режим любого вида всегда создает особую социальнопсихологическую атмосферу в исправительном учреждении, охватывающую всю совокупность занятых там людей и их действий. Исключительная же роль режима в системе основных средств исправления 
осужденных заключается в том, что он создает необходимые условия для эффективного применения других средств исправления (труда, обучения, воспитательной работы), а также для саморегуляции правопослушного поведения осужденного посредством создания надлежащих условий, а также через организационную, контрольную, воспитательную и предупредительную деятельность администрации.

В то же время, как совершенно верно подчеркивают специалисты, выполнение требований режима обеспечивается принудительно, но обусловлено это не задачами карательного воздействия на осужденных, а прежде всего заботой обеспечения безопасности самих осужденных, персонала и иных лиц, посещающих исправительные учреждения, и необходимостью профилактики правонарушений (Antonyan, 2018: 10). Вместе с тем, анализ состояния дисциплинарной практики среди осужденных к лишению свободы и уровень преступности в исправительных учреждениях свидетельствуют о явных недоработках в данном направлении деятельности, поскольку уже на протяжении нескольких лет наблюдается устойчивая тенденция роста как уровня нарушений режима осужденными, так и преступности среди отбывающих лишение свободы в исправительных учреждениях. Уровень роста показателя нарушений режима порядка отбывания наказания в расчете на 1000 человек в 2018 г. составил $3,5 \%$, а в 2019 г.- 11,1 \%. Общий уровень преступности в учреждениях УИС в 2018 г. вырос на 5,2 \%, а в 2019 г. на 1000 человек составил 0,926 , что на $21 \%$ больше, чем в предыдущем.

Становится очевидным, что режим, выполняющий функцию общего предупреждения преступлений и обеспечения социального контроля за поведением осужденных и лиц, находящихся на территории исправительного учреждения, в настоящее время демонстрирует свою неэффективность.

Следующим и не менее важным средством исправления осужденных является общественно полезный труд. Для достиже- ния цели исправления осужденные, отбывающие лишение свободы, привлекаются к труду, который в соответствии со ст. 103 УИК РФ для них обязателен.

Вместе с тем, привлечение осужденных к общественно полезному труду не может рассматриваться как принудительный труд в силу того, что труд изначально входит в содержание отбывания наказания в виде лишения свободы, что раскрывается в нормах как международных нормативных актов (например, подп. «с» п. 2 ст. 2 Конвенции Международной организации труда № 29 от 28 июня 1930 г., подп. «с» п. 3 ст. 8 Международного пакта о гражданских и политических правах от 16 декабря 1966 г.), так и отечественного законодательства. Порядок, условия и ограничения привлечения осужденных к труду устанавливаются в соответствии с общими требованиями законодательства РФ о труде, а также нормами уголовно-исполнительного законодательства. Так, ст. 103 УИК РФ устанавливает требование к администрации исправительных учреждений привлекать осужденных к труду с учетом их пола, возраста, трудоспособности, состояния здоровья и по возможности специальности, а также исходя из наличия рабочих мест. Помимо этого вопросы привлечения осужденных к работам по хозяйственному обслуживанию учреждений, исполняющих наказания, регламентируются Законом РФ от 21 июля 1993 г. № 5473-1 «Об учреждениях и органах, исполняющих уголовные наказания в виде лишения свободы».

Кроме того, как подчеркивают А. В. Бриллиантов и С.И. Курганов, исключительно в целях исправления осужденных законодателем введено нормативное положение ст. 3 Закона РФ «О занятости населения в Российской Федерации», закрепившее гарантию лица, осужденного к лишения свободы, в период отбывания наказания не быть признанным безработным (Brilliantov, Kurganov, 2018: 341). Однако вопрос трудовой занятости осужденных в местах лишения свободы всегда стоял крайне остро. Некоторые исследователи к числу негативных факторов, 
сопровождающих трудовую деятельность осужденных, относят следующие: условия труда осужденных не отвечают общепринятым нормам и правилам; рабочие места не оснащены современным оборудованием; частое отсутствие возможности выбора рода занятия; ограниченность территории осуществления работы (Krivopalova, 2020: 38). В настоящее время одной из ключевых проблем является действующий механизм привлечения осужденных к оплачиваемому труду, который требует полной самоокупаемости и наличия финансового результата и не предусматривает федерального финансирования данной государственной функции. В том числе это сказывается на наличии самих рабочих мест, однако работа в данном направлении проводится. Так, по данным Научно-исследовательского института информационных технологий ФСИН России, в 2019 г. в исправительных учреждениях организовано производство 2315 новых изделий, что позволило трудоустроить 20329 человек из числа осужденных, среднесписочная численность осужденных, трудоустроенных на сезонных сельскохозяйственных работах, составила 2047 человек, а занятых в сфере животноводства - 3430 человек (Osnovnye pokazateli deyatel'nosti.., 2020).

Общественно полезный труд для осужденных как средство исправления также предполагает выполнение работ по благоустройству мест отбывания наказания, по обеспечению надлежащего порядка, в том числе по соблюдению правил санитарии и гигиены в местах их проживания, работы и имеет своей целью оказание непосредственной пользы как коллективу осужденных, так и администрации исправительного учреждения.

Труд осужденных, будучи составной частью организации исполнения наказания в виде лишения свободы, обязательно предусмотрен в распорядке дня каждого исправительного учреждения, а нарушение в этой сфере может повлечь применение мер взыскания, материальную ответственность, а также признание осужденного злостным нарушителем установленного порядка отбывания наказания.

Общеизвестно, что одной из важнейших составляющих характеристики любой личности является уровень образования. Не исключение и личность осужденного, отбывающего лишение свободы. Исходя из этого получение общего образования служит неотъемлемой частью процесса исправления осужденных к лишению свободы и выделено в качестве самостоятельного средства исправления.

В соответствии с Федеральным законом от 29 декабря 2012 г. № 273-Ф3 «Об образовании в Российской Федерации» право каждого человека на образование гарантируется государством. Получение образования - конституционное право каждого осужденного, однако обязательность получения основного общего образования установлена ст. 112 УИК РФ для осужденных к лишению свободы, не достигших 30 лет. Порядок организации получения осужденными общего образования регламентируется Положением об организации получения основного общего и среднего (полного) общего образования лицами, отбывающими наказание в виде лишения свободы в исправительных колониях и тюрьмах уголовноисполнительной системы, утвержденным совместным приказом Министерства юстиции России и Министерства образования и науки России от 6 декабря 2016 г. № 274/1525.

Процесс организации общеобразовательного обучения осужденных в местах лишения свободы основывается на общих принципах государственного образования, таких как всеобщность, обязательность, доступность, светскость, но с определенной корректировкой. Прежде всего, это связано с расположением школ и учебноконсультационных пунктов непосредственно на территории исправительных учреждений и соответствующими требованиями режима отбывания наказания.

В настоящее время образовательный процесс в исправительных учреждениях организован в 267 вечерних общеобразовательных школах и 510 учебно- 
консультационных пунктах. На начало 2019/20 учебного года, согласно данным официальной статистики ФСИН России, в исправительных учреждениях зарегистрировано 62464 обучающихся при общем количестве осужденных, подлежащих обязательному обучению, 50871 человек. Исходя из приведенных сведений, можно сделать вывод о том, что все осужденные, подлежащие обязательному общему обучению, выполняют свою прямую обязанность - устранять пробелы в своих знаниях.

Продолжая рассмотрение основных средств исправления, необходимо отметить, что наряду с обязанностью для осужденных в период отбывания лишения свободы получить основное общее образование (до 30 лет) законодателем установлена обязанность получить и начальное профессиональное образование или пройти профессиональную подготовку для всех трудоспособных осужденных, не имеющих профессии (специальности), по которой они могли бы работать как в исправительном учреждении, так и после освобождения из него (ч. 1 ст. 108 УИК РФ). Таким образом, ст. 9 УИК РФ профессиональное обучение осужденных отнесено к числу основных средств исправления.

Рассматривая правовое регулирование организации профессионального обучения осужденных, нельзя не заметить явно прослеживаемую взаимосвязь с таким средством исправления, как труд осужденных, поскольку без должного профессионального образования качественный и высокопроизводительный труд осужденных просто невозможен. Именно поэтому вопросы труда осужденных, их профессионального образования и профессионального обучения рассматриваются нормами одной главы, а именно главы 14 УИК РФ «Труд, профессиональное образование и профессиональное обучение осужденных к лишению свободы».

В соответствии с ч. 1 ст. 108 УИК РФ в исправительных учреждениях организуется обязательное профессиональное обучение или среднее профессиональное образование по программам подготовки квалифицированных рабочих, служащих осужденных к лишению свободы, не имеющих профессии (специальности), по которой осужденный может работать в исправительном учреждении и после освобождения из него. На сегодняшний день обучение осужденных в образовательных учреждениях ФСИН России проводится по 2473 различным наименованиям профессий. Статистика ФСИН России свидетельствует, что общая численность осужденных, получивших квалификацию по профессии и привлеченных к труду в исправительных учреждениях на начало 2019 г., составила 68365 человек, а по различным причинам без профессии (специальности) было освобождено 1060 человек.

Положительным моментом профессионального обучения является его близость к повседневной производственной деятельности, в процессе которой осужденные закрепляют и совершенствуют полученные знания и навыки. Формы профессионального обучения могут быть самыми разнообразными: школы, курсы, бригадное или индивидуальное обучение и т. д.

Вместе с тем, как устанавливает законодатель и, что немаловажно, подтверждается на практике, отношение к получению образования (профессиональному обучению) всегда является одним из часто используемых администрацией исправительных учреждений оснований как применения к осужденным мер поощрения, так и наложения мер взысканий в случае уклонения или невыполнения данной обязанности. Помимо этого стремление осужденных к получению основного общего образования либо дополнительного профессионального образования всегда должно расцениваться как стремление к исправлению, как намерение изменить свой образ жизни после освобождения.

Относительно новым и, по нашему мнению, не в полной мере урегулированным в уголовно-исполнительном законодательстве России, вызывающим вопрос о целесообразности выделения в качестве самостоятельного средства исправления осужденных является такое средство, как 
общественное воздействие. Мы полностью разделяем замечание профессора Б. З. Маликова о том, что «уголовно-исполнительное законодательство не раскрывает сущности общественного воздействия на осужденных, однако прямо или косвенно указывает на некоторые формы этой работы...» (Malikov, 2018: 146).

Следует заметить, что общественное воздействие как средство исправления осужденных по аналогии с некоторыми иными средствами не нашло закрепления в отдельной норме Уголовно-исполнительного кодекса, которая бы определяла понятие, раскрывала содержание, формы и направления общественного воздействия на осужденных. Довольно подробно законодательное понятие «общественное воздействие на осужденных» отражено в научно-теоретической модели Уголовноисполнительного кодекса Российской Федерации, подготовленной коллективом авторов под научной редакцией профессора В.И. Селиверстова (Seliverstov, 2016: 237). Согласно ч. 1 ст. 31 указанного документа общественное воздействие на осужденных подразумевает под собой основанную на законодательстве Российской Федерации социально полезную деятельность институтов гражданского общества и граждан, осуществляемую субъектами общественного воздействия совместно с учреждениями и органами, исполняющими уголовные наказания и иные меры уголовно-правового характера, и направленную на обеспечение достижения цели исправления осужденных.

В науке уголовно-исполнительного права доминирует позиция, что «общественное воздействие как основное средство исправления осужденных находится в неразрывной связи с другими средствами исправления, дополняет их и может являться их внутренним обязательным структурным элементом» (Popova, 2014: 214). По нашему мнению, общественное воздействие реализуется путем участия ее субъектов в организации и проведении с осужденными воспитательной работы, направленной на их идейно- нравственное, гражданско-правовое, трудовое, эстетическое и физическое воспитание.

В настоящее время роль общественных институтов в деятельности уголовноисполнительной системы и оказываемого ими воздействия на процесс исправления осужденных активно возрастает. Значение общественного воздействия как средства исправления прежде всего проявляется в повышении эффективности проводимых администрацией учреждений и органов, исполняющих наказания, мероприятий различного характера, имеющих основной целью исправление осужденных и оказания им помощи после освобождения.

Но все же пристальное внимание обращают на себя проблемные вопросы в реализации такого средства исправления осужденных, как воспитательная работа. Так, существующие нормы уголовно-исполнительного законодательства (ч. 3 ст. 109 УИК РФ) закрепляют обязанность осужденного посещать лишь воспитательные мероприятия, которые закреплены распорядком дня исправительного учреждения. При этом примерный распорядок дня для осужденных, утвержденный в ПВР ИУ (Приложением № 6), устанавливает продолжительность ежедневных воспитательных мероприятий лишь до одного часа. В таких же учреждениях, как воспитательная колония, воспитательные мероприятия проводятся по отдельному графику в пределах полутора часов ежедневно. Как правило, данные мероприятия организуются в групповой или массовой формах и подразумевают под собой просмотр телепередач, прослушивание лекций, участие осужденных в различных спортивных мероприятиях, кружковую работу и др. Неучастие в подобных мероприятиях может рассматриваться администрацией как нарушение требований режима.

Однако ошибочно полагать, что воспитательная работа как средство исправления сводится лишь к обязательному привлечению осужденных к воспитательным мероприятиям, закрепленным в распорядке дня исправительного учреждения, или иным культурно-массовым мероприятиям, про- 
водимым по отдельному графику. К сожалению, в настоящее время в исправительных учреждениях часто имеют место случаи, когда отбывающие там лишение свободы осужденные со ссылкой на необязательность посещения воспитательных мероприятий ввиду их отсутствия в распорядке дня исправительного учреждения категорически отказываются от посещения и участия в них. И это одна из серьезных проблем реализации воспитательной работы как средства исправления осужденных, поскольку воспитательная работа представляет собой комплекс индивидуальных, групповых и массовых мер по распространению и утверждению общечеловеческих и общественно значимых ценностей, признаваемых и защищаемых государством и обществом, направленных на выработку у осужденных убеждения в добросовестном отношении ко всем средствам исправления, формирование их гражданской позиции, готовности строго следовать предписаниям закона и нормам человеческого общежития (Sirakov, 2007: 8).

Подчеркивая важное значение воспитательной работы как средства исправления осужденных, нельзя не согласиться с мнением А.М. Потапова, который при рассмотрении вопроса организации данной деятельности в исправительных учреждениях подчеркивает: «...учитывая направленность воспитательной работы на личность осужденного или на их коллектив в целом, следует указать, что без активной позиции осужденных данное средство исправления реализоваться не сможет» (Potapov, 2014: 9).

Выходом из сложившейся ситуации может стать анализ международного опыта нормативно-правового регулирования рассматриваемой сферы деятельности уголовно-исполнительной системы России. На наш взгляд, в первую очередь изучению подлежит опыт государств участников Содружества Независимых Государств, поскольку общей целью уголовно-исполнительного законодательства данных государств является унификация, то есть достижение единообразного регулирования общественных отношений в сфере исполнения уголовных наказаний и применения к осужденным исправительного воздействия. В этой связи интерес правового обеспечения осуществления воспитательного воздействия на осужденных к лишению свободы вызывает уголовно-исполнительное законодательство Республики Беларусь. Так, ч. 3 ст. 104 УИК Республики Беларусь устанавливает, что посещение осужденными проводимых воспитательных мероприятий является обязательным. На наш взгляд, имплементация в подобной формулировке указанной правовой нормы в ч. 3 ст. 109 УИК РФ «Воспитательная работа с осужденными к лишению свободы» значительно упростит порядок привлечения осужденных к воспитательным мероприятиям, проводимым сотрудниками администрации исправительных учреждений (индивидуальные воспитательные беседы, заслушивание на заседаниях совета воспитателей отряда и др.), и повысит качество реализации данного средства исправления осужденных.

Кроме того, считаем целесообразным по аналогии, как этого требует УИК Республики Беларусь (ст. 187), закрепить в ч. 2,3 и 3.1 ст. 175 УИК РФ необходимость обязательно отражать в характеристике на осужденного при решении вопроса о целесообразности условно-досрочного освобождения или замены неотбытой части наказания более мягким видом наказания сведения, подтверждающие достижение осужденным определенной степени исправления, которая характеризуется помимо его поведения, отношения в течение всего периода отбывания наказания к учебе и труду, к совершенному деянию и возмещению вреда (возместил полностью или частично), причиненного преступлением, также и проявленной полезной инициативой при участии в групповых формах воспитательной работы. Утвержденные ФСИН России методические рекомендации по эффективной организации воспитательной работы гласят, что групповые формы воспитательной работы предполагают проведение 
воспитательных мероприятий в формате социально-правовых занятий (лекций), общих собраний осужденных, викторин, конкурсов, а также кружковой работы.

\section{Заключение}

Таким образом, подводя итог изучению проблем правового регулирования реализации основных средств исправления осужденных к лишению свободы в уголовноисполнительном законодательстве, можно сделать следующие выводы:

1. Такое средство исправления осужденных, как общественное воздействие, в настоящее время в уголовно-исполнительном законодательстве остается не в полной мере урегулированным и по большей части проявляется как внутренний элемент такого средства исправления, как воспитательная работа, что ставит под сомнение целесообразность выделения его ст. 9 УИК РФ в качестве самостоятельного средства исправления. Рациональным решением представляется перенос и более подробное нормативное регулирование вопроса участия общественных объединений в исправлении осужденных к лишению свободы в главу 15 УИК РФ «Воспитательное воздействие на осужденных к лишению свободы».

2. Повышению эффективности реализации такого средства исправления осужденных, как воспитательная работа, a именно законодательного закрепления обязанности для осужденных к лишению свободы посещения воспитательных мероприятий, будет способствовать имплементация нормы права, регулирующая данную обязанность осужденных в УИК Республики Беларусь. Исходя из этого, ч. 3 ст. 109 УИК РФ необходимо представить в следующей редакции: «Посещение осужденными проводимых воспитательных мероприятий является обязательным».

3. В характеристике на осужденного о достижение определенной степени исправления при решении вопроса о целесообразности условно-досрочного освобождения или замены неотбытой части наказания более мягким видом наказания в соответствии с ч. 2, 3 и 3.1. ст. 175 УИК РФ также должно быть обязательно отмечено отношение к проводимым воспитательным мероприятиям, а именно проявленной полезной инициативы при участии в групповых формах воспитательной работы.

Указанные изменения нормативно-правового регулирования средств исправления осужденных к лишению свободы способны значительно повысить эффективность достижения цели уголовно-исполнительного законодательства как исправление осужденных.

\section{Список литературы / References}

Antonyan, E.A. (2018). Ispravitel'noe vozdejstvie na osuzhdennyh [Correctional impact on the convicts].Moscow, Prospekt, $144 \mathrm{p}$.

Bebeen, V.G. (2008) Obschestvennoe vozdeistvie kak sredstvo ispravleniya nesovershennoletnih osujdennih [Educational activities as a means of correction and the subsequent social adaptation of persons convicted to deprivation of liberty]. Avtoref. dis $\backslash . .$. kand. ped. nauk. Moscow. 44p.

Brilliantov, A.V., Kurganov, S.I. (2018). Kommentarij k Ugolovno-ispolnitel'nomu kodeksu Rossijskoj Federacii (postatejnyj) [Commentary on the Criminal Executive Code of the Russian Federation (itemized)].Moscow, Prospekt, 576p.

Federal Penitentiary Service (2020). Available at: https://www.youtube.com/watch?v=TA6o

d-AjfrU (accessed 19 August 2020). (1)

Krivopalova, A.A (2020) Problemy privlecheniya k trudu osuzhdennyh k lisheniyu svobody [Problems of labour convicted to deprivation of liberty] In Vestnik samarskogo yuridicheskogo institute [Bulletin of samara legal institute],3(39), 37-41.DOI 10.37523/SUI.2020.39.3.005

Malikov, B.Z. (2018). Obshchestvennoe vozdejstvie - sredstvo ispravleniya osuzhdennyh, i rol' v nem religioznogo aspekta [Social impact - a means of correcting the convicted, and the role of the religious aspect in it]. In Ugolovno-ispolnitel'noe pravo [Criminal enforcement law], 2, 146-151. 
Valery N. Belik, Nikolay N. Kutakov... Problems of Legal Regulation of the Implementation of Fixed Assets of Legal...

Matveenko V.E. (2000) Obschestvennoe vozdeistvie kak sredstvo ispravleniya nesovershennoletnih osujdennih [Social Revival as a means of correcting juvenile convicts]. Dis.l. ... kand. law. nauk. Ryazan. $242 \mathrm{p}$.

Mikhlin, A.S., Seliverstov, V. I. (2008). Kommentarij k Ugolovno-ispolnitel'nomu kodeksu Rossijskoj Federacii [Commentary on the Criminal Executive Code of the Russian Federation].Moscow, YUrajt, $585 \mathrm{p}$.

Osnovnye pokazateli deyatel'nosti ugolovno-ispolnitel'noj sistemy (yanvar'-dekabr' 2019 g.): informacionno-analiticheskij sbornik [Key performance indicators of the penitentiary system (JanuaryDecember 2019)]. Tver, 2020, 359 p. (2)

Popova, E.E. (2014). Obshchestvennoe vozdejstvie v sisteme v sisteme sredstv ispravleniya osuzhdennyh [Public impact in the system in the system of means of correction of convicts], In YUridicheskaya nauka i praktika [Legal science and practice].212-214.

Potapov, A.M. (2014). Organizaciya vospitatel'noj raboty s osuzhdennymi [Organization of educational work with convicts]. Vologda, VIPE FSIN Rossii, 235 p.

Seliverstov, V.I. (2016). Nauchno-teoreticheskaya model' Ugolovno-ispolnitel'nogo kodeksa Rossijskoj Federacii [Scientific and theoretical model of the Criminal Executive code of the Russian Federation]. In Problemy ukrepleniya zakonnosti i pravoporyadka: nauka, praktika, tendencii [Problems of strengthening law and order: science, practice, trends], 9, 235-242.

Seliverstov, V.I. (2018) Ispravitel'naya doktrina i ee vliyanie na polozhenie lic, osvobozhdennyh ot otbyvaniya nakazaniya [Correctional doctrine and its impact on the situation of persons released from serving a sentence] In YUridicheskij vestnik Samarskogo universiteta [Legal Bulletin of Samara University], T.4, $2,65-73$.

Sirakov, A.N. (2007). Organizacionno-pravovye voprosy vospitatel'noj raboty s osuzhdennymi k lisheniyu svobody: istoricheskie aspekty i sovremennost' [Organizational and legal issues of educational work with persons sentenced to imprisonment: historical aspects and modernity].Available at: http://www.crimpravo.ru/blog/731.html (accessed 24 April 2020).

Teplyashin, P.V. (2020). Optimization principles of penal execution system of Russia in the context of European penitentiary practice. J. Sib. Fed. Univ. Humanit. Soc. Sci., 13(1), 123-131. DOI: 10.17516/1997$1370-0539$.

Uporov, I.V. (2017) Popytki reformirovaniya penitenciarnoj sistemy Rossii vo vtoroj polovine XIX veka [Attempts to reform the penitentiary system of Russia in the second half of the XIX century] In Problemy sovremennoj nauki i innovacii [Problems of modern science and innovation], 5, 5-10.

Utkin, V.A. (2019) Progressivnaya sistema ispolneniya lisheniya svobody v Rossii na rubezhe XIX$\mathrm{XX}$ vv. [Progressive system of execution of imprisonment in Russia at the turn of the XIX-XX centuries] In Vestnik Tomskogo gosudarstvennogo universiteta. Pravo. [Tomsk State University Journal of Law], 33, 153-159. DOI: $10.17223 / 22253513 / 33 / 14$

Vishnevskaya, N.I. (2006) Ispravlenie osuzhdennyh k lisheniyu svobody: voprosy teorii i praktiki: ugolovno-ispolnitel'nyj aspekt [Correction of persons sentenced to deprivation of liberty: issues of theory and practice: the criminal-Executive aspect]. Avtoref. dis $\$. ... kand. law. nauk. Chelyabinsk. P. 26.

Yuzanin, V.E., Gorban, D.V. (2018) Rezhim i mery preduprezhdeniya pravonarushenij sredi osuzhden$n y h v$ sisteme ispolneniya nakazaniya $v$ vide lisheniya svobody [Regime and measures for the prevention of offences among convicted persons in the system of execution of sentences in the form of deprivation of liberty]. Ryazan, Academy of law and management of the Federal penitentiary service of Russia, $428 \mathrm{p}$. 